\title{
Price discovery in the markets for credit risk: A Markov switching approach
}

\author{
Thomas Dimpfl* \\ Franziska J. Peter*
}

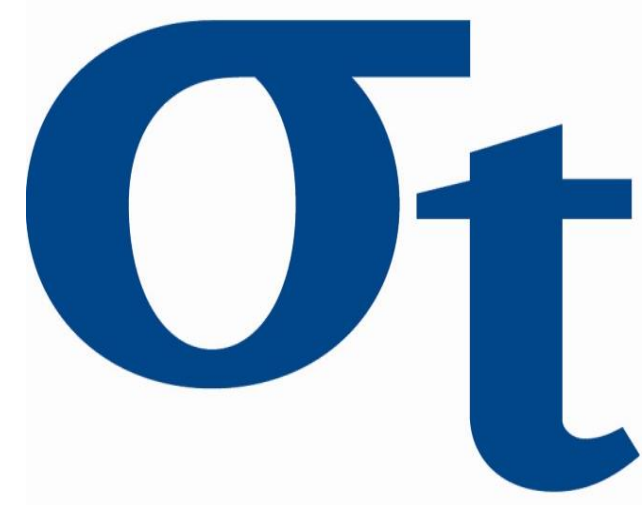




\title{
Price discovery in the markets for credit risk: A Markov switching approach
}

\author{
Thomas Dimpf* Franziska J. Peter*
}

20th July 2015

\begin{abstract}
We examine price discovery in the Credit Default Swap and corporate bond market. By using a Markov switching framework we are able to analyze the dynamic behavior of the information shares during tranquil and crisis periods. The results show that price discovery takes place mostly on the CDS market. The importance of the CDS market even increases during the more volatile crisis periods. According to a cross sectional analysis liquidity is the main determinant of a market's contribution to price discovery. During the crisis period, however, we also find a positive link between leverage and CDS market information shares. Overall the results indicate that price discovery measures and their determinants change during tranquil and crisis periods, which emphasizes the importance of more flexible frameworks, such as Markov switching models.
\end{abstract}

Keywords: Markov switching model, price discovery, credit risk, CDS; JEL classification: C14, G15

${ }^{*}$ University of Tuebingen. Department of Statistics, Econometrics and Empirical Economics, Mohlstrasse 36, 72074 Tuebingen, Germany.

Corresponding author: Franziska Julia Peter, University of Tuebingen, Department of Statistics, Econometrics and Empirical Economics, Mohlstrasse 36, 72074 Tuebingen, Germany, Phone: +497071 29 78165. Fax: +49 7071 29 5546. Email: franziskajulia.peter@uni-tuebingen.de. This research project is funded by the German Research Foundation (DFG) grant GR 2288, data are provided through the DFG SFB 649 'Economic Risk' 


\section{Introduction}

The markets for credit risk have recently attracted a great attention in finance literature. Particularly, the reaction of the Credit Default Swap (CDS) market to the crisis period of 2007-2009 has been analyzed, as it allows researchers to derive information that may help to maintain financial market stability in more volatile periods. In this context information transmission between markets is of paramount interest. One of the key questions is how the processes of price discovery reacts to changes in the market environment, such as a serious financial crisis. In order to examine this issue we use a Markov switching framework to analyze the dynamics of the price discovery process between the markets for credit risk, i.e. the CDS and corporate bond market during tranquil and crisis periods. Furthermore, we examine potential factors that influence a markets importance for the price discovery process and whether these change during more volatile times.

The pronounced regime specific behavior displayed by CDS spreads has been previously documented by Alexander and Kaeck (2008) and Leppin and Reitz (2014) among others. Both studies report changes in the dynamics of CDS prices depending on high and low volatility regimes.However, previous price discovery studies have neglected this characteristic. Blanco et al. (2005), Dimpfl and Peter (2013) and Grammig and Peter (2013) examine the contribution of the CDS and corporate bond market to the price discovery process. All of them determine the CDS market as the leading one. Blanco et al. (2005) apply the common measure of Hasbrouck (1995) information shares to quantify a market's contribution. The Hasbrouck information share measure was modified by Grammig and Peter (2013), in order to resolve the problem of underterminancy inherent in the Hasbrouck approach and deliver a unique information share. Our approach extends their methodology by using a Markov switching framework that models CDS prices and bond spreads dependent on two different variance regimes. This approach renders a unique information share measure along the lines of Hasbrouck (1995) and at the same time accounts for regime dependent behaviour. We thereby rely on a model recently proposed by Herwartz and Luetkepohl (2014), which identifies shocks in a autoregressive system with Markov switching by combining conventional with statistical identification methods. Applying their model to the context of price discovery allows a much more accurate assessment concerning the informationally leading market.

We analyze CDS and bond spread time series on 24 European iTraxx reference entities during a period of January 1, 2004 to December 31, 2011. Consistent with previous studies we find that the CDS market leads price discovery for most reference entities. During more volatile periods the leadership 
of the CDS market becomes even more pronounced. Concerning potential determinants of information shares we find that relative liquidity matters. During volatile periods, however, there also exists a positive link between leverage and the CDS market information share. This indicates that in a volatile environment the CDS market plays a prominent role in the price discovery process for companies with a higher default risk. With respect to the recent financial crisis, these results indicate that the importance of the CDS market is even more pronounced during crisis periods for firms with a higher default risk.

The remainder of the paper is organized as follows. Section 2 shortly outlines the Hasbrouck (1995) information shares and introduces the Markov switching model and the corresponding information shares. Section 3 describes the data and estimation procedure. In Section 4 we present the estimated information shares and their determinants derived from a crosssectional regression. Section 5 concludes.

\section{A Markov switching approach to estimate unique information shares}

In the following we briefly outline the Hasbrouck (1995) methodology and subsequently introduce the Markov switching model. Assuming pairwise cointegrated prices in $n$ markets, price dynamics can be described by a Vector Error Correction Model (see Hasbrouck (1995)):

$$
\Delta \mathbf{p}_{t}=\boldsymbol{\alpha} \boldsymbol{\beta}^{\prime} \mathbf{p}_{t-1}+\Gamma_{1} \Delta \mathbf{p}_{t-1}+\ldots+\Gamma_{q-1} \Delta \mathbf{p}_{t-q+1}+\mathbf{u}_{t}
$$

where $\boldsymbol{\beta}$ is the $n \times n$ cointegration matrix, $\boldsymbol{\alpha}$ denotes a $n \times n$ matrix that contains the adjustment coefficients, and the $\boldsymbol{\Gamma}$ s are $n \times n$ parameter matrices that govern the autoregressive behavior of the price series. Furthermore $\mathbf{u}_{t} \sim$ $\left(\mathbf{0}, \boldsymbol{\Sigma}_{\mathbf{u}}\right)$, are composite innovations. Within the Hasbrouck (1995) framework composite innovations are modeled as linear combination of iid idiosyncratic innovations, i.e $\mathbf{u}_{t}=\mathbf{B} \varepsilon_{t}$ where $\varepsilon_{t} \sim\left(\mathbf{0}, \mathbf{I}_{n}\right)$. B denotes a $n \times n$ matrix whose elements capture the contemporaneous effect of the idiosyncratic innovations.

According to Hasbrouck (1995) the common efficient price $\boldsymbol{p}_{t}^{*}$ follows a random walk where $\boldsymbol{v}_{\boldsymbol{t}}$ are the efficient price innovations. Assuming that initial prices are zero $\boldsymbol{p}_{\mathbf{0}}^{*}=0$, the efficient price series relates to the VECM parameters by

$$
p_{t}^{*}=v_{t}+v_{t-1}, \ldots=\xi^{\prime} \mathrm{B}\left(\varepsilon_{t}+\varepsilon_{t-1}+\ldots\right)
$$


$\boldsymbol{\xi}$ gives the vector of long run impacts of the idiosyncratic innovations that can be derived as the common row vector of $\Xi=\boldsymbol{\beta}_{\perp}\left[\boldsymbol{\alpha}_{\perp}^{\prime}\left(\mathbf{I}_{n}-\sum_{i=1}^{q-1} \boldsymbol{\Gamma}_{i}\right) \boldsymbol{\beta}_{\perp}\right]^{-1} \boldsymbol{\alpha}_{\perp}^{\prime}$, where $\boldsymbol{\alpha}_{\perp}$ denotes the orthogonal complement of $\boldsymbol{\alpha}$ (see Johansen (1995)).

Hasbrouck's information shares are then defined as the share in the variance of the efficient price innovation which is attributed to each of the markets. Consequently, decomposing the efficient price innovation variance given by

$$
\operatorname{Var}\left(v_{t}\right)=\boldsymbol{\xi}^{\prime} \boldsymbol{\Sigma}_{\mathbf{u}} \boldsymbol{\xi}=\boldsymbol{\xi}^{\prime} \mathbf{B B}^{\prime} \boldsymbol{\xi}
$$

results in the vector of information shares (IS):

$$
\mathbf{I S}=\frac{\left[\boldsymbol{\xi}^{\prime} \mathbf{B}\right]^{(2)}}{\boldsymbol{\xi}^{\prime} \mathbf{B B}^{\prime} \boldsymbol{\xi}}
$$

The main drawback of this approach is that matrix $\mathbf{B}$ which contains the contemporaneous effects is underidentified. From equation (1) we can estimate the covariance matrix $\boldsymbol{\Sigma}_{\boldsymbol{u}}$ which relates to $\mathbf{B}$ by $\boldsymbol{\Sigma}_{\boldsymbol{u}}=\mathbf{B} \mathbf{B}^{\prime}$. However, as $\boldsymbol{\Sigma}_{\boldsymbol{u}}$ is symmetric, we can only identify $\frac{n^{2}+n}{2}+n$ of the $n^{2}$ elements in $\mathbf{B}$.

Hasbrouck proposes decomposing $\boldsymbol{\Sigma}_{\mathbf{u}}=\mathbf{B} \mathbf{B}^{\prime}$ using the Cholesky decomposition. Thereby we replace $\mathbf{B}$ by the lower triangular matrix $\mathbf{C}$ resulting from the Cholesky decomposition of $\boldsymbol{\Sigma}_{\boldsymbol{u}}$. The Hasbrouck information shares then given by

$$
\text { HIS }=\frac{\left[\boldsymbol{\xi}^{\prime} \mathbf{C}\right]^{(2)}}{\boldsymbol{\xi}^{\prime} \mathbf{C C}^{\prime} \boldsymbol{\xi}}
$$

Applying the Cholesky decomposition involves ruling out certain contemporaneous effects. The ordering of the markets becomes important as shocks in the market ordered first can instantly influence all other markets, while the contemporaneous effects of the market ordered last are restricted to zero. This results in an upper bound estimate for the information share of the market ordered first and a lower bound estimate of the last ordered market's information share. Permuting the ordering yields lower and upper bounds for each market.

As outlined by Grammig and Peter (2013) information share upper and lower bounds can be large depending on the amount of contemporaneous correlation between the composite innovations $\mathbf{u}_{\mathbf{t}}$ (compare Booth et al. (2002) and Hupperets and Menkveld (2002)). As a result conclusions regarding the leading market are vage. Grammig and Peter (2013) resolve this problem by assuming a mixture normal distribution for the composite innovations. This assumption is supported by the commonly found fat tails in financial returns (see Longin and Solnik (2001); Rigobon (2003); Lanne and Lütkepohl $(2010)$ ) and enables the identification of contemporaneous effects and unique 
information shares. In the context of Grammig and Peter $(2013)$ the distributional assumption imply two regimes that are associated with different variances. The regimes are assumed to be independent (iid).

In the current approach we use a less restrictive assumption concerning the regimes. We assume that the two regimes are not iid, but depend on a Markov process $s_{t}$ (see Lanne et al. (2010a); Herwartz and Luetkepohl (2014)). Furthermore we assume that conditioning on state $s$ at time $t$, the composite innovations $\mathbf{u}_{\mathbf{t}}$ are normally distributed with covariance $\boldsymbol{\Sigma}_{\boldsymbol{s}_{\boldsymbol{t}}}$, i.e. $\mathbf{u}_{\mathbf{t}} \mid s_{t} \sim \mathcal{N}\left(\mathbf{0}, \boldsymbol{\Sigma}_{\boldsymbol{s}_{t}}^{\boldsymbol{u}_{\boldsymbol{t}}}\right)$, where $s_{t}$ is generated by a discrete Markov chain of first order with transition probabilities: $p_{i j}=P\left(s_{t}=j \mid s_{t-1}=i\right) \forall i, j \in\{1,2\}$.

The idiosyncratic innovations $e_{t}$ are either from state 1 or state 2 , where the states are described by different variances and therefore

$$
\mathbf{e}_{t}= \begin{cases}\mathbf{e}_{1, t} \sim N\left(\mathbf{0}, \mathbf{I}_{n}\right) & \text { with prob. } p \\ \mathbf{e}_{2, t} \sim N(\mathbf{0}, \mathbf{\Psi}) & \text { with prob. } 1-p\end{cases}
$$

where $p=P\left(s_{t}=1\right)=\frac{1-p_{22}}{2-p_{11}-p_{22}}$ gives the unconditional probability of regime 1 (see Hamilton (1994)). $\boldsymbol{\Psi}$ is a diagonal matrix with distinct elements. It follows that the composite innovations are given by $\mathbf{u}_{\mathbf{t}}=B \varepsilon_{t}=\mathbf{W e}_{\mathbf{t}}$ with covariance matrix $\Sigma_{u}=W \Sigma_{e} W^{\prime}=W\left(p I_{n}+(1-p) \Psi\right)$.

According to equation (5) the vector of information shares is derived as

$$
\mathbf{I S}=\frac{\left[\xi^{\prime} \mathbf{W}\left(p \mathbf{I}_{n}+(1-p) \boldsymbol{\Psi}\right)^{0.5}\right]^{(2)}}{\xi^{\prime} \mathbf{W}\left(p \mathbf{I}_{n}+(1-p) \mathbf{\Psi}\right) \mathbf{W}^{\prime} \xi} .
$$

The identification of the contemporaneous effects within this framework demands for certain assumptions concerning the second regime covariance matrix, $\boldsymbol{\Psi}$, as well as the matrix of contemporaneous effects, $\mathbf{W}$. The second regime variances i.e. the diagonal elements of $\boldsymbol{\Psi}$ have to be distinct (for a formal proof see Grammig and Peter (2013) and Lanne et al. (2010b). Furthermore Grammig and Peter (2013) show that for unique identification additional restrictions have to be imposed on $\mathbf{W}$. These restrictions are

$$
w_{i, i}>0 \quad \forall \quad i \text { and } w_{i, i}>\left|w_{j, i}\right| \quad \forall \quad j \neq i
$$

where $w_{i, j}$ denotes the row $i$, column $j$ element of $\mathbf{W}$. These restrictions arise naturally within the price discovery framework, where we observe $n$

\footnotetext{
${ }^{1}$ Modeling regime (or time) dependent VECM parameters is possible (compare Doetz (2007), however, it is not conformable with the microstructure model at the base of the Hasbrouck (1995) methodology. Therefore, the economic meaning of information shares derived from such a framework is questionable.
} 
prices that rely on the same underlying asset. They imply that the effect of an idiosyncratic market $i$ price shock $\left(e_{i, t}\right)$ on the observed market price $\left(p_{i, t}\right)$ has to be of the same sign as the shock itself. Furthermore, the contemporaneous effect of an idiosyncratic shock originating in market $i\left(e_{i, t}\right)$ on the own market price $\left(p_{i, t}\right)$ is greater than the contemporaneous effect on all other prices. Based on these assumptions the information shares in equation (7) are uniquely determined ${ }^{2}$

\section{$3 \quad$ Estimation and data}

Estimation is performed in two steps. First, the VECM in equation (1) is estimated by means of ordinary least squares. Using the residual series, $\mathbf{u}_{\mathbf{t}}$, i.e. the composite innovations, estimates for the matrix of contemporaneous effects $\mathbf{W}$ and the second regime covariance matrix $\boldsymbol{\Psi}$ are obtained via Maximization-likelihood. Thereby, two strategies are pursued to obtain Maximum-likelihood estimates. Within the first approach, the log-likelihood function is optimized directly. The alternative strategy is the ExpectationMaximization algorithm adapted for the Markov-switching framework (see Herwartz and Luetkepohl (2014); Lanne et al. (2010b) and Krolzig (1997)). Standard errors for the estimated parameters are based on a parametric bootstrap (compare Grammig and Peter (2013); Davidson and MacKinnon $(2000)$ ). Details concerning the estimation and bootstrap procedure are outlined in the Appendix.

Our data set includes CDS and bond time series of 24 iTraxx companies ranging from January 1, 2004 to December 31, 2011 (2085 observations). The sample includes those reference entities which are constituents of the iTraxx Europe index and for which sufficient CDS and bond data was available during the sample period, in order to construct CDS and bond spread times series. CDS premia data are obtained from Datastream. Following Blanco et al. (2005) and Doetz (2007), we use 5-year contracts as they are most liquid. The corresponding bond yield series are calculated from bonds with different maturities using linear interpolation, so that the constructed time series of bond yields matches the constant 5-years maturity of the CDS time series (for details see Dimpfl and Peter (2013)). In order to avoid measurement errors due to various options in bonds, we only include bonds with fixed rate, which are not callable, puttable or convertible. Finally we calculate bond spreads as the difference between the risky bond yields and the risk-free interest rate.

${ }^{2}$ The formal proof with Markov switching innovations works analogous to Grammig and Peter (2013). 
We use the 5-year swap rates as a proxy for the risk free rate. Bonds and swap series are obtained from Bloomberg.

Insert Figure 1 here

Table A.1 in the Appendix gives details on our sample reference entities. Figure 1 depicts the CDS and credit spread time series for each reference entity.

\section{Estimation results}

\subsection{Credit risk price discovery with two variance regimes}

Table 1 shows estimation results for the second regime variances, the transition probabilities and unconditional probability for state 1 (the state 2 probability equals $1-p$ ) as well as the CDS market information share (the bond market information share equals $\left.100-I S_{C D S}\right)$.

The estimated values for the diagonal elements of $\boldsymbol{\Psi}$ show that the second regime is governed by a higher variance compared to the first regime. Thereby idiosyncratic innovations in the CDS market exhibit a relative higher second regime variance compared to the bond market estimate $\left(\hat{\Psi}_{1}>\hat{\mathbf{\Psi}}_{2}\right)$. The estimated transition probabilities indicate that the regimes are not iid. $p_{11}$ and $p_{22}$ estimates are mostly near unity, which implies that conditional on being in a specific state in time $t$, the probability to remain in this state is large. These results correspond to previous findings by Alexander and Kaeck (2008).

\section{Insert table 1 here}

Concerning price discovery, the estimated information shares imply that overall the CDS market is the informational dominant market. For 21 out of 24 reference entities the CDS information share exceeds 50\%, for 13 reference entities price discovery almost exclusively takes place on the CDS market, as the estimated information shares are above $90 \%$.

These results are in line with previous studies. However, they allow a much more accurate assessment of the leading market in price discovery. While, for instance information shares upper and lower bounds in Blanco et al. (2005) vary by up to 25 percentage points, our results deliver a unique measure. In addition, the Markov switching nature of our model allows to 
examine the dynamic behavior of the information shares. By using the filtered and smoothed regime probabilities, we can generate a time series of information shares. Figure 2 depicts the development of CDS market information shares for each reference entity during the sample period. The graphs show that for several reference entities, such as Bayer (BAY) or Iberdrola (IBE), the CDS information share in the second state is considerably higher compared to the first regime information shares. For these reference entities the regime switches to the high volatility state around the onset of the financial crisis and remains predominantly in the high volatility regime until the end of our sampling period (December 31, 2011). The importance of the CDS market compared to the bond market obviously increases during periods associated with a higher volatility.

\section{Insert figure 2 here}

We further examine this issue by calculating regime specific information shares. Note that the following is not generally in line with the Hasbrouck (1995) methodology and the underlying microstructure model. However, in this particular application, the pre crisis period is dominated by the low volatility regime and the crisis and post crisis period by the high volatility regime. Therefore calculating regime dependent information shares can yield additional insights. Regime dependent information shares are derived by assuming that $p=1$ in equation (5) to derive first regime information shares and $p=0$ to derive second regime information shares. Results for the CDS market information shares are displayed in table 2 .

\section{Insert table 2 here}

The results show that the importance of the CDS market is larger during the high volatility compared to the low volatility regime for most reference entities. Exceptions are FTE, VAT and VOW, for which, the CDS market information share is close to unity in both regimes.

A possible explanation for these findings is increased insider trading in the CDS market during the crisis period as reported by Coro et al. (2013). They explore the credit and liquidity determinants of CDS price movements and investigate how their role changed as a result of the 2007-2009 financial crisis. They find that informed trading has a more prominent impact on CDS prices during the crisis period. However, they examine CDS prices only. In order to determine whether informed traders actually prefer trading on the CDS market rather than the bond market during crisis periods the changes of the extent of informed trading on both markets had to be analyzed. Nevertheless, comparing overall CDS information shares to the regime dependent 
information shares, it becomes obvious that the results are driven by the high volatility regime. Our analysis emphasize the importance of the CDS market for price discovery during crisis periods.

\subsection{Information share determinants}

In order to gain some insights into possible determinants of information shares, we conduct cross-sectional regressions. As explanatory variables we use firm specific characteristics, such as industry, market capitalization and the debt/equity ratio as a measure of a company's financial leverage. Furthermore, we proxy for relative liquidity of the CDS and bond market by using the ratio between CDS and bond market bid-ask spreads in both markets? The dependent variable is the CDS market information share, to which we applied the logit transformation to account for that fact that information shares lie between zero and one (i.e. the dependent variable in each regression is $\left.\ln \frac{I S_{C D S}}{1-I S_{C D S}}\right)$. Table 3 shows the resulting parameter estimates. Each column corresponds to one regression. In the first regression we included all explanatory variables outlined above. Significant parameters were found only for the constant, the liquidity ratio and the debt/equity ratio. The negative coefficient on relative liquidity implies that decreasing liquidity in the CDS relative to the bond market (i.e. an increasing CDS market spread and/or decreasing bond market spread) is associated with a lower CDS market information share. This conclusion is in line with the positive link between liquidity and contributions to price discovery derived in previous studies (see Kehrle and Peter (2013); Chen et al. (2013)).

Insert table 3 here

An interesting results is the positive significant coefficient on the debt/equity ratio. This implies that higher leverage increases the CDS market information share relative to the bond market share. In table 4 we run regressions of the regime dependent information shares on the liquidity proxy and the debt/equity ratio.

Insert table 4 here

\footnotetext{
${ }^{3}$ Bid-ask spreads in the CDS market are calculated from daily bid and ask prices, while the bond market bid-ask spread is proxied by taking the average over spreads proxied by the Roll model (Roll (1984)) for each bond series used for interpolation. Data on market capitalization, industries, and book debt/equity ratios are from Compustat.
} 
The results show that while relative liquidity is an important factor regardless of the volatility regime, a company's leverage matters for price discovery only in the high volatility regime. Consequently, CDS trading is more informative compared to the bond market during volatile periods and when a company faces a higher credit risk. This results supports the hypothesis of a higher level of insider trading in the CDS market during periods of severe credit deterioration shocks (see Acharya and Johnson (2007) and Forte and Lovreta (2009)). These findings show that CDS trading is most important when a company faces severe credit risk increases. Particularly, during crisis periods and for companies with a high credit risk, the CDS market is obviously the market where prices are set. 


\section{Conclusion}

We propose a Markov switching framework to model price discovery between the CDS and corporate bond market. The advantage of our approach lies in delivering a unique measure while accounting for regime switching behavior of shocks. When analyzing 24 iTraxx companies we determine the CDS as the informationally dominant market. The CDS market information share even increases during more volatile periods. Furthermore, we examine potential determinants for a markets contribution to the price discovery process by conducting cross-sectional regressions. The results support previous evidence of a positive link between liquidity and information shares. Firm specific characteristics such as market capitalization or industry are not found to be statistically significant. However, we document an impact of a reference entity's leverage on information shares, indicating that the importance of the CDS market relative to the bond market increases with higher leverage ratios. This relationship is more pronounced during volatile periods. Our results emphasize the role of the CDS market for the price discovery process of credit risk in particular during crisis periods. 


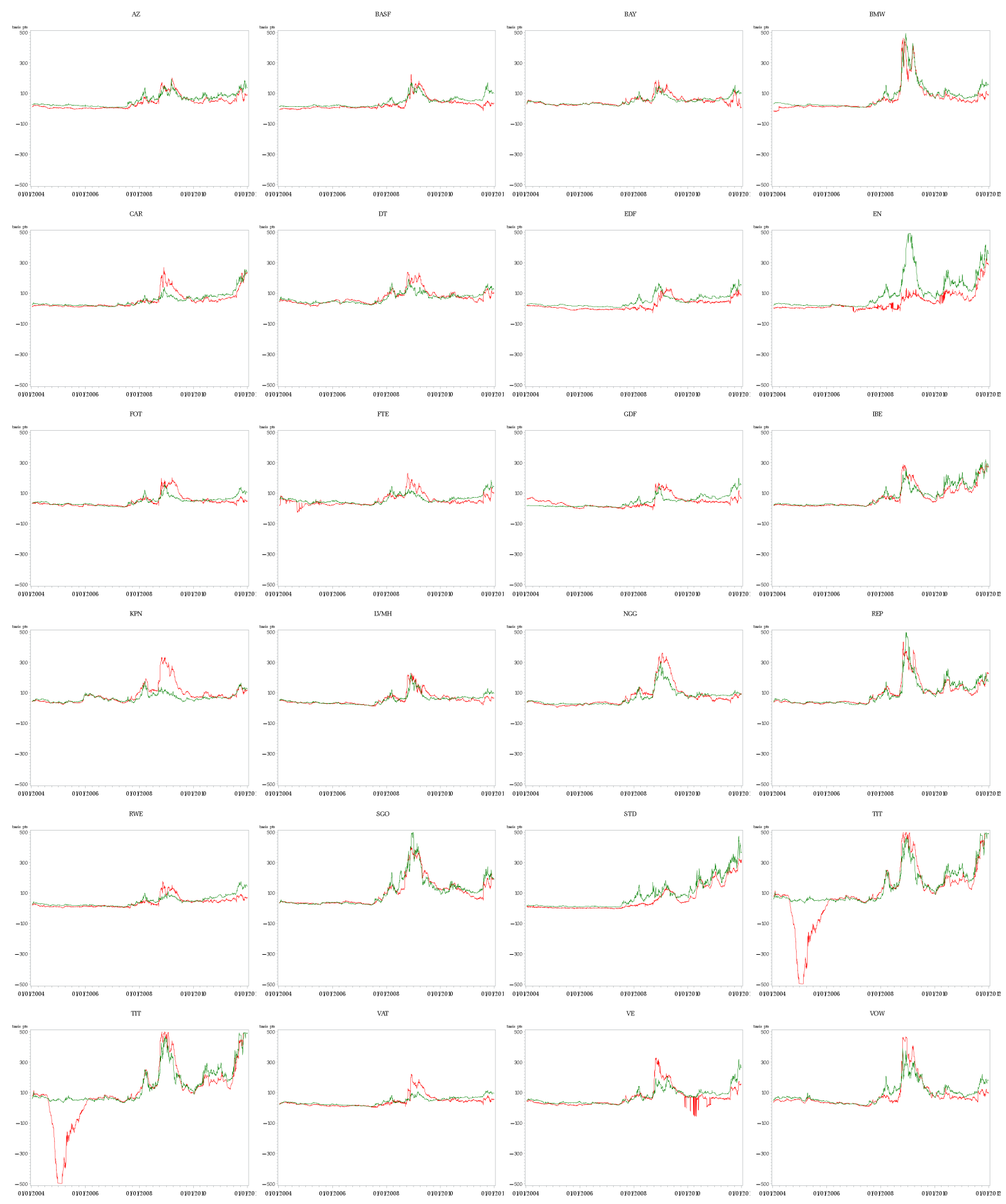

Figure 1: CDS and bond spread time series. The figure shows the CDS and bond spread time series for each reference entity. 


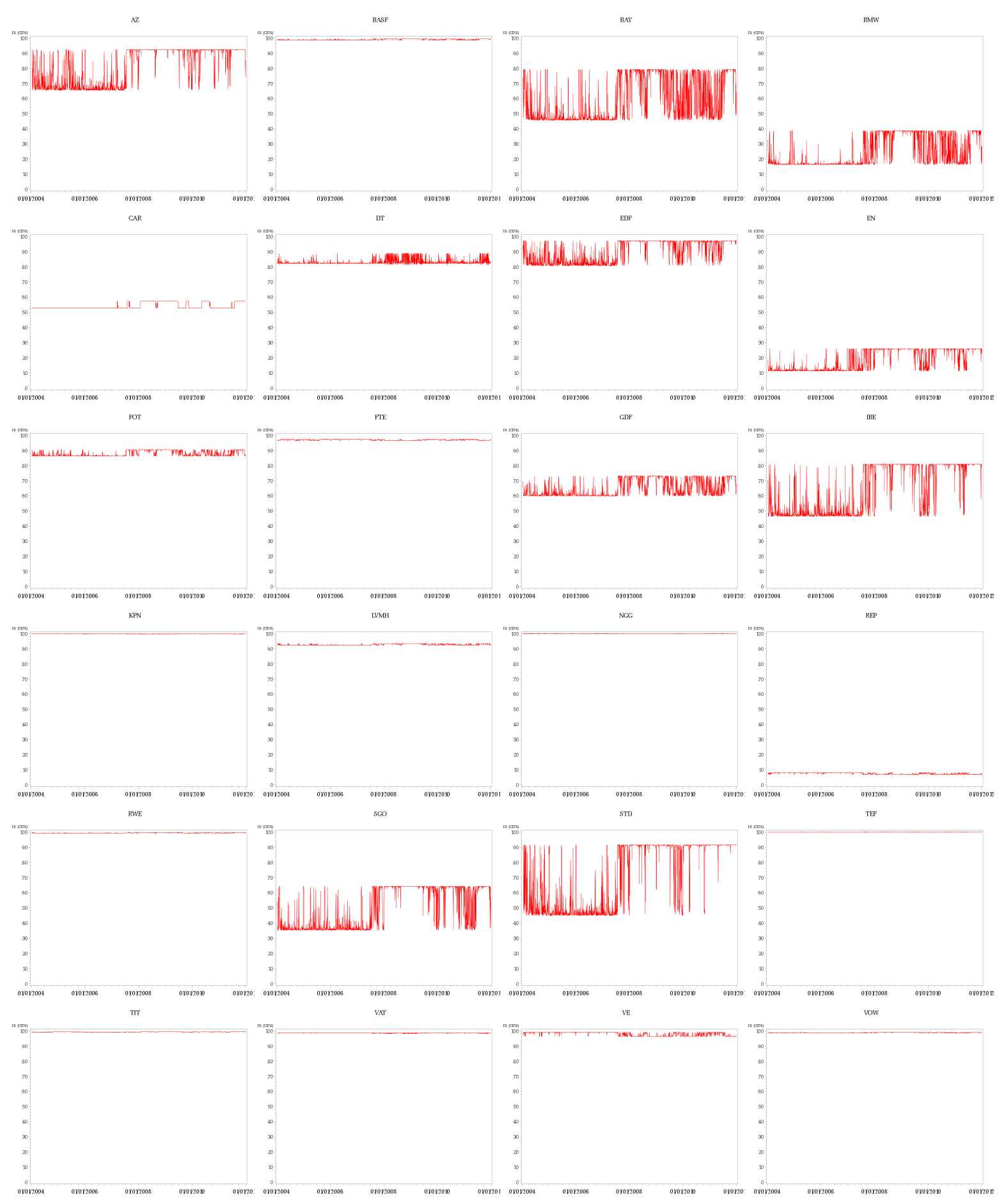

Figure 2: Filtered CDS market information share time series. The figure shows the time series of the filtered CDS market information shares for each reference entity. The information share time series were calculated by using the smoothed unconditional regime probabilities. 


\begin{tabular}{|c|c|c|c|c|c|c|c|c|}
\hline TICKER & $\Psi_{B}$ & $\Psi_{C D S}$ & $p_{11}$ & $p_{12}$ & $p_{21}$ & $p_{22}$ & $p$ & $I S_{C D S}$ \\
\hline $\mathrm{AZ}$ & $\begin{array}{c}9.20 \\
(0.55)\end{array}$ & $\begin{array}{l}63.41 \\
(4.02)\end{array}$ & $\begin{array}{c}0.97 \\
(0.01)\end{array}$ & $\begin{array}{c}0.04 \\
(0.00)\end{array}$ & $\begin{array}{c}0.03 \\
(0.00)\end{array}$ & $\begin{array}{c}0.96 \\
(0.01)\end{array}$ & $\begin{array}{c}0.52 \\
(0.00)\end{array}$ & $\begin{array}{c}91.65 \\
(11.29)\end{array}$ \\
\hline BASF & $\begin{array}{l}14.15 \\
(1.01)\end{array}$ & $\begin{array}{l}36.67 \\
(2.39)\end{array}$ & $\begin{array}{c}0.97 \\
(0.00)\end{array}$ & $\begin{array}{c}0.09 \\
(0.00)\end{array}$ & $\begin{array}{c}0.03 \\
(0.00)\end{array}$ & $\begin{array}{c}0.91 \\
(0.01)\end{array}$ & $\begin{array}{c}0.72 \\
(0.00)\end{array}$ & $\begin{array}{c}99.33 \\
(10.06)\end{array}$ \\
\hline BAY & $\begin{array}{c}11.89 \\
(0.81)\end{array}$ & $\begin{array}{l}58.33 \\
(4.11)\end{array}$ & $\begin{array}{c}0.95 \\
(0.01)\end{array}$ & $\begin{array}{c}0.13 \\
(0.00)\end{array}$ & $\begin{array}{c}0.05 \\
(0.00)\end{array}$ & $\begin{array}{c}0.87 \\
(0.02)\end{array}$ & $\begin{array}{c}0.73 \\
(0.00)\end{array}$ & $\begin{array}{c}76.23 \\
(21.11)\end{array}$ \\
\hline BMW & $\begin{array}{l}35.06 \\
(2.42)\end{array}$ & $\begin{array}{l}120.23 \\
(8.81)\end{array}$ & $\begin{array}{c}0.96 \\
(0.01)\end{array}$ & $\begin{array}{c}0.12 \\
(0.00)\end{array}$ & $\begin{array}{c}0.04 \\
(0.00)\end{array}$ & $\begin{array}{c}0.88 \\
(0.01)\end{array}$ & $\begin{array}{c}0.74 \\
(0.00)\end{array}$ & $\begin{array}{c}37.43 \\
(18.68)\end{array}$ \\
\hline CAR & $\begin{array}{l}18.64 \\
(1.44)\end{array}$ & $\begin{array}{l}23.64 \\
(1.77)\end{array}$ & $\begin{array}{c}0.97 \\
(0.00)\end{array}$ & $\begin{array}{c}0.09 \\
(0.00)\end{array}$ & $\begin{array}{c}0.03 \\
(0.00)\end{array}$ & $\begin{array}{c}0.91 \\
(0.01)\end{array}$ & $\begin{array}{c}0.01 \\
(0.00)\end{array}$ & $\begin{array}{c}73.29 \\
(21.75)\end{array}$ \\
\hline DT & $\begin{array}{c}8.65 \\
(1.24)\end{array}$ & $\begin{array}{l}17.69 \\
(2.39)\end{array}$ & $\begin{array}{c}0.98 \\
(0.01)\end{array}$ & $\begin{array}{c}0.06 \\
(0.00)\end{array}$ & $\begin{array}{c}0.02 \\
(0.00)\end{array}$ & $\begin{array}{c}0.94 \\
(0.00)\end{array}$ & $\begin{array}{c}0.93 \\
(0.00)\end{array}$ & $\begin{array}{c}68.80 \\
(19.99)\end{array}$ \\
\hline EDF & $\begin{array}{l}16.31 \\
(1.01)\end{array}$ & $\begin{array}{l}150.59 \\
(11.60)\end{array}$ & $\begin{array}{c}0.94 \\
(0.01)\end{array}$ & $\begin{array}{c}0.09 \\
(0.00)\end{array}$ & $\begin{array}{c}0.06 \\
(0.00)\end{array}$ & $\begin{array}{c}0.91 \\
(0.01)\end{array}$ & $\begin{array}{c}0.59 \\
(0.00)\end{array}$ & $\begin{array}{c}96.76 \\
(12.25)\end{array}$ \\
\hline EN & $\begin{array}{l}43.31 \\
(2.79)\end{array}$ & $\begin{array}{c}127.52 \\
(8.79)\end{array}$ & $\begin{array}{c}0.95 \\
(0.01)\end{array}$ & $\begin{array}{c}0.07 \\
(0.00)\end{array}$ & $\begin{array}{c}0.05 \\
(0.00)\end{array}$ & $\begin{array}{c}0.93 \\
(0.01)\end{array}$ & $\begin{array}{c}0.57 \\
(0.00)\end{array}$ & $\begin{array}{c}25.65 \\
(28.13)\end{array}$ \\
\hline FOT & $\begin{array}{l}15.13 \\
(1.05)\end{array}$ & $\begin{array}{l}23.28 \\
(1.51)\end{array}$ & $\begin{array}{c}0.97 \\
(0.00)\end{array}$ & $\begin{array}{c}0.07 \\
(0.00)\end{array}$ & $\begin{array}{c}0.03 \\
(0.00)\end{array}$ & $\begin{array}{c}0.93 \\
(0.01)\end{array}$ & $\begin{array}{c}0.73 \\
(0.00)\end{array}$ & $\begin{array}{c}89.94 \\
(15.17)\end{array}$ \\
\hline FTE & $\begin{array}{l}21.74 \\
(1.49)\end{array}$ & $\begin{array}{c}16.89 \\
(1.11)\end{array}$ & $\begin{array}{c}0.96 \\
(0.01)\end{array}$ & $\begin{array}{c}0.10 \\
(0.00)\end{array}$ & $\begin{array}{c}0.04 \\
(0.00)\end{array}$ & $\begin{array}{c}0.90 \\
(0.01)\end{array}$ & $\begin{array}{c}0.70 \\
(0.00)\end{array}$ & $\begin{array}{c}96.55 \\
(16.04)\end{array}$ \\
\hline $\mathrm{G}$ & $\begin{array}{l}11.85 \\
(0.81)\end{array}$ & $\begin{array}{l}22.13 \\
(1.54)\end{array}$ & $\begin{array}{c}0.96 \\
(0.01)\end{array}$ & $\begin{array}{c}0.10 \\
(0.00)\end{array}$ & $\begin{array}{c}0.04 \\
(0.00)\end{array}$ & $\begin{array}{c}0.90 \\
(0.01)\end{array}$ & $\begin{array}{c}0.73 \\
(0.00)\end{array}$ & $\begin{array}{c}71.21 \\
(20.56)\end{array}$ \\
\hline IBE & $\begin{array}{l}13.70 \\
(0.84)\end{array}$ & $\begin{array}{l}71.07 \\
(4.55)\end{array}$ & $\begin{array}{c}0.97 \\
(0.01)\end{array}$ & $\begin{array}{c}0.04 \\
(0.00)\end{array}$ & $\begin{array}{c}0.03 \\
(0.00)\end{array}$ & $\begin{array}{c}0.96 \\
(0.01)\end{array}$ & $\begin{array}{c}0.57 \\
(0.00)\end{array}$ & $\begin{array}{c}79.65 \\
(15.37)\end{array}$ \\
\hline $\mathrm{KPN}$ & $\begin{array}{l}11.87 \\
(2.85)\end{array}$ & $\begin{array}{l}13.29 \\
(2.49)\end{array}$ & $\begin{array}{c}0.97 \\
(0.01)\end{array}$ & $\begin{array}{c}0.08 \\
(0.00)\end{array}$ & $\begin{array}{c}0.03 \\
(0.00)\end{array}$ & $\begin{array}{c}0.92 \\
(0.00)\end{array}$ & $\begin{array}{c}0.95 \\
(0.00)\end{array}$ & $\begin{array}{c}84.76 \\
(24.41)\end{array}$ \\
\hline LVMH & $\begin{array}{l}24.85 \\
(1.85)\end{array}$ & $\begin{array}{l}29.65 \\
(2.08)\end{array}$ & $\begin{array}{c}0.97 \\
(0.00)\end{array}$ & $\begin{array}{c}0.10 \\
(0.00)\end{array}$ & $\begin{array}{c}0.03 \\
(0.00)\end{array}$ & $\begin{array}{c}0.90 \\
(0.01)\end{array}$ & $\begin{array}{c}0.76 \\
(0.00)\end{array}$ & $\begin{array}{c}93.26 \\
(16.77)\end{array}$ \\
\hline NGG & $\begin{array}{c}12.12 \\
(0.87)\end{array}$ & $\begin{array}{l}34.73 \\
(2.44)\end{array}$ & $\begin{array}{c}0.97 \\
(0.00)\end{array}$ & $\begin{array}{c}0.07 \\
(0.00)\end{array}$ & $\begin{array}{c}0.03 \\
(0.00)\end{array}$ & $\begin{array}{c}0.93 \\
(0.01)\end{array}$ & $\begin{array}{c}0.73 \\
(0.00)\end{array}$ & $\begin{array}{c}99.94 \\
(11.73)\end{array}$ \\
\hline $\mathrm{R}$ & $\begin{array}{l}25.94 \\
(2.85)\end{array}$ & $\begin{array}{l}58.42 \\
(2.21)\end{array}$ & $\begin{array}{c}0.96 \\
(0.01)\end{array}$ & $\begin{array}{c}0.07 \\
(0.00)\end{array}$ & $\begin{array}{c}0.04 \\
(0.00)\end{array}$ & $\begin{array}{c}0.93 \\
(0.01)\end{array}$ & $\begin{array}{c}0.66 \\
(0.00)\end{array}$ & $\begin{array}{l}43.35 \\
(6.40)\end{array}$ \\
\hline RWE & $\begin{array}{l}10.93 \\
(0.75)\end{array}$ & $\begin{array}{l}24.55 \\
(1.64)\end{array}$ & $\begin{array}{c}0.96 \\
(0.01)\end{array}$ & $\begin{array}{c}0.09 \\
(0.00)\end{array}$ & $\begin{array}{c}0.04 \\
(0.00)\end{array}$ & $\begin{array}{c}0.91 \\
(0.01)\end{array}$ & $\begin{array}{c}0.70 \\
(0.00)\end{array}$ & $\begin{array}{c}99.50 \\
(12.94)\end{array}$ \\
\hline SGC & $\begin{array}{l}19.05 \\
(1.18)\end{array}$ & $\begin{array}{r}65.59 \\
(4.15)\end{array}$ & $\begin{array}{c}0.97 \\
(0.01)\end{array}$ & $\begin{array}{c}0.05 \\
(0.00)\end{array}$ & $\begin{array}{c}0.03 \\
(0.00)\end{array}$ & $\begin{array}{c}0.95 \\
(0.01)\end{array}$ & $\begin{array}{c}0.58 \\
(0.00)\end{array}$ & $\begin{array}{c}62.94 \\
(17.06)\end{array}$ \\
\hline STD & $\begin{array}{c}8.62 \\
(0.52)\end{array}$ & $\begin{array}{l}124.58 \\
(8.92)\end{array}$ & $\begin{array}{c}0.97 \\
(0.01)\end{array}$ & $\begin{array}{c}0.03 \\
(0.00)\end{array}$ & $\begin{array}{c}0.03 \\
(0.00)\end{array}$ & $\begin{array}{c}0.97 \\
(0.01)\end{array}$ & $\begin{array}{c}0.53 \\
(0.00)\end{array}$ & $\begin{array}{l}90.47 \\
(8.08)\end{array}$ \\
\hline $\mathrm{T}$ & $\begin{array}{l}15.30 \\
(0.98)\end{array}$ & $\begin{array}{l}40.23 \\
(2.61)\end{array}$ & $\begin{array}{c}0.96 \\
(0.01)\end{array}$ & $\begin{array}{c}0.07 \\
(0.00)\end{array}$ & $\begin{array}{c}0.04 \\
(0.00)\end{array}$ & $\begin{array}{c}0.93 \\
(0.01)\end{array}$ & $\begin{array}{c}0.64 \\
(0.00)\end{array}$ & $\begin{array}{c}99.86 \\
(7.76)\end{array}$ \\
\hline TIT & $\begin{array}{l}20.37 \\
(1.32)\end{array}$ & $\begin{array}{c}27.64 \\
(1.81)\end{array}$ & $\begin{array}{c}0.95 \\
(0.01)\end{array}$ & $\begin{array}{c}0.07 \\
(0.00)\end{array}$ & $\begin{array}{c}0.05 \\
(0.00)\end{array}$ & $\begin{array}{c}0.93 \\
(0.01)\end{array}$ & $\begin{array}{c}0.57 \\
(0.00)\end{array}$ & $\begin{array}{c}99.25 \\
(25.95)\end{array}$ \\
\hline VAT & $\begin{array}{l}18.51 \\
(5.22)\end{array}$ & $\begin{array}{l}17.76 \\
(3.89)\end{array}$ & $\begin{array}{c}0.97 \\
(0.01)\end{array}$ & $\begin{array}{c}0.12 \\
(0.00)\end{array}$ & $\begin{array}{c}0.03 \\
(0.00)\end{array}$ & $\begin{array}{c}0.88 \\
(0.00)\end{array}$ & $\begin{array}{c}0.96 \\
(0.00)\end{array}$ & $\begin{array}{c}99.70 \\
(15.14)\end{array}$ \\
\hline VE & $\begin{array}{c}122.38 \\
(9.26)\end{array}$ & $\begin{array}{l}28.74 \\
(1.91)\end{array}$ & $\begin{array}{c}0.96 \\
(0.01)\end{array}$ & $\begin{array}{c}0.10 \\
(0.00)\end{array}$ & $\begin{array}{c}0.04 \\
(0.00)\end{array}$ & $\begin{array}{c}0.90 \\
(0.01)\end{array}$ & $\begin{array}{c}0.70 \\
(0.00)\end{array}$ & $\begin{array}{c}96.43 \\
(15.49)\end{array}$ \\
\hline V & $\begin{array}{l}30.21 \\
(2.07)\end{array}$ & $\begin{array}{l}43.09 \\
(2.84)\end{array}$ & $\begin{array}{c}0.97 \\
(0.00)\end{array}$ & $\begin{array}{c}0.09 \\
(0.00)\end{array}$ & $\begin{array}{c}0.03 \\
(0.00)\end{array}$ & $\begin{array}{c}0.91 \\
(0.01)\end{array}$ & $\begin{array}{c}0.72 \\
(0.00)\end{array}$ & $\begin{array}{l}98.94 \\
(9.58)\end{array}$ \\
\hline
\end{tabular}

Table 1: Estimation results. The table shows the estimation results for the second regime variances of idiosyncratic innovation $\$$ ff the bond and CDS markets $\left(\Psi_{B}, \Psi_{C D S}\right)$, the transition probabilities $\left(p_{i j}\right)$, and the unconditional probability of the first regime $(p)$. The last column ontains the estimated CDS market information shares $\left(I S_{C D S}\right)$. Standard errors derived by a parametric bootsrap are in parentheses. 


\begin{tabular}{llll}
\hline & & & \\
TICKER & $I S_{C D S}$ & $I S_{C D S}^{\text {Regime }}$ & IS \\
& & & \\
\hline & & & \\
AZ & 91.65 & 63.59 & 92.33 \\
BASF & 99.33 & 98.44 & 99.39 \\
BAY & 76.23 & 43.43 & 79.02 \\
BMW & 37.43 & 15.55 & 38.70 \\
CAR & 73.29 & 68.39 & 73.29 \\
DT & 68.80 & 61.30 & 76.40 \\
EDF & 96.76 & 77.70 & 96.99 \\
EN & 25.65 & 10.68 & 26.04 \\
FOT & 89.94 & 85.98 & 90.42 \\
FTE & 96.55 & 97.22 & 96.46 \\
GDF & 71.21 & 59.20 & 73.04 \\
IBE & 79.65 & 44.86 & 80.84 \\
KPN & 84.76 & 84.15 & 85.60 \\
LVMH & 93.26 & 92.60 & 93.15 \\
NGG & 99.94 & 99.85 & 99.95 \\
REP & 43.35 & 26.11 & 44.31 \\
RWE & 99.50 & 99.00 & 99.55 \\
SGO & 62.94 & 34.14 & 64.09 \\
STD & 90.47 & 42.35 & 91.39 \\
TEF & 99.86 & 99.66 & 99.87 \\
TIT & 99.25 & 99.00 & 99.26 \\
VAT & 99.70 & 99.70 & 99.69 \\
VE & 96.43 & 99.08 & 96.21 \\
VOW & 98.94 & 98.52 & 98.96 \\
& & & \\
\hline
\end{tabular}

Table 2: Regime specific information shares. The table shows the CDS market information share (column 2) together with regime specific information shares (column 3 and 4). Regime 1 corresponds to the low volatility period and regime 2 to the high volatility period. 


\begin{tabular}{lccc} 
VARIABLE & IS $_{C D S}$ & IS $_{C D S}$ & IS $_{C D S}$ \\
\hline INTERCEPT & $4.09^{*}$ & $4.67^{* * *}$ & $6.25^{* * *}$ \\
& $(2.19)$ & $(1.28)$ & $(1.14)$ \\
LIQUIDITY & $-3.86^{*}$ & $-4.56^{* * *}$ & $-5.47^{* * *}$ \\
& $(2.06)$ & $(1.53)$ & $(1.60)$ \\
DEBT/EQUITY & $1.97^{* *}$ & $1.43^{*}$ & - \\
MARKET CAP. & $(0.80)$ & $(0.69)$ & \\
& -8.76 & - & - \\
INDUSTRY TMT & $(12,01)$ & & - \\
& 0.51 & - & - \\
INDUSTRY FIN & $(1.39)$ & & - \\
INDUSTRY ENERGY & 0.73 & - & \\
\hline ADJUSTED R & $(1.83)$ & & 0.37 \\
\hline
\end{tabular}

Table 3: Regression Results. The table shows regression results for regressions of the transformed CDS market information share on firm specific and market specific factors. The omitted industry dummy includes all remaining sample industries (industrials, automobiles, consumers). Standard errors are in parentheses. $* * *, * *, *$ indicate significance at the 1,5 , and $10 \%$ level.

\begin{tabular}{ccc}
\hline VARIABLE & IS $_{C D S}^{\text {Regime1 }}$ & IS $_{C D S}^{\text {Regime } 2}$ \\
\hline INTERCEPT & $4.04^{* *}$ & $4.11^{* *}$ \\
& $(1.57)$ & $(1.45)$ \\
LIQUIDITY & $-5.36^{* *}$ & $-4.49^{* *}$ \\
& $(1.88)$ & $(1.73)$ \\
DEBT/EQUITY & 1.46 & $1.87^{* *}$ \\
& $(0.85)$ & $(0.78)$ \\
\hline ADJUSTED R $\mathrm{R}^{2}$ & 0.42 & 0.46 \\
\hline
\end{tabular}

Table 4: Regime specific regression results. The table shows regression results using the logit transformed regime dependent CDS market information share estimates as dependent variable. 


\section{References}

Acharya, V. V., and T. C. Johnson (2007): "Insider trading in credit derivatives," Journal of Financial Economics, 84(1), 110-141.

Alexander, C., And A. Kaeck (2008): "Regime dependent determinants of credit default swap spreads," Journal of Banking $\&$ Finance, 32(6), $1008-1021$.

Blanco, R., S. Brennan, and I. W. Marsh (2005): "An empirical analysis of the dynamic relation between investment-grade nonds and credit default swaps," Journal of Finance, 60, 2255-2281.

Booth, G., J.-C. Lin, T. Martikainen, and Y. Tse (2002): "Trading and pricing in upstairs and downstairs stock markets," Review of Financial Studies, 15, 1111-1135.

Chen, H., P. M. S. Choi, And Y. Hong (2013): "How smooth is price discovery? Evidence from cross-listed stock trading," Journal of International Money and Finance, 32, 668-699.

Coro, F., A. Dufour, and S. Varotto (2013): "Credit and liquidity components of corporate CDS spreads," Journal of Banking 85 Finance, $37(12), 5511-5525$.

Davidson, R., And J. G. MacKinnon (2000): Econometric Theory and Methods. Oxford University Press, Oxford.

Dimpfl, T., And F. J. Peter (2013): "Using transfer entropy to measure information flows between financial markets," Studies in Nonlinear Dynamics and Econometrics, 17, 85-102.

Doetz, N. (2007): "Time-varying contributions by the corporate bond and CDS markets to credit risk price discovery," Discussion Paper Series 2: Banking and Financial Studies.

Forte, S., And L. LovReta (2009): "Credit risk discovery in the stock and CDS Markets: Who Leads, when, and why," Working Paper.

Grammig, J., And F. J. Peter (2013): "TellTale Tails: A new approach to estimate unique market information shares," Journal of Financial and Quantitative Analysis, 48, 459-488.

Hamilton, J. (1994): Time Series Analysis. Princeton University Press, Princeton, New Jersey. 
HASBRouCK, J. (1995): "One security, many markets: determining the contributions to price discovery," Journal of Finance, 50, 1175-1199.

Herwartz, H., And H. Luetkepohl (2014): "Structural vector autoregressions with Markov switching: Combining conventional with statistical identification of shocks," Journal of Econometrics, forthcoming.

Hupperets, E. C., And A. J. Menkveld (2002): "Intraday analysis of market integration: Dutch Blue Chips traded in Amsterdam and New York," Journal of Financial Markets, 5, 57-82.

Johansen, S. (1995): Likelihood-based inference in cointegrated vector autoregressive models. Oxford University Press, Oxford.

Kehrle, K., And F. J. Peter (2013): "Who moves first? An intensity based measure for information flows between stock exchanges," Journal of Banking \& Finance, 37, 1629-1642.

KrolzIG, H.-M. (1997): Markov-switching vector autoregressions: Modelling, statistical inference, and application to business cycle analysis. Springer-Verlag, Berlin.

LANNe, M., AND H. LÜTKEPOHL (2010): "Structural vector autoregression with nonnormal residuals," Journal of Business and Economic Statistics, 28, 159-168.

Lanne, M., H. LÜtKePohl, and K. Maciejowska (2010a): "Structural vector autoregressions with Markov switching," Journal of Economic Dynamcis and Control, 34, 121-131.

(2010b): "Structural Vector Autoregressions with Markov Switching," Journal of Economic Dynamics and Control, 34, 121-131.

Leppin, J. S., AND S. Reitz (2014): "The role of a changing market environment for credit default swap pricing," FinMaP-Working Papers.

Longin, F., And B. SolniK (2001): "Extreme correlation of international equity markets," Journal of Finance, 56, 649-676.

Rigobon, R. (2003): "Identification through Heteroskedasticity," Review of Economics and Statistics, 85, 777-792.

RolL, R. (1984): "A simple implicit measure of the effective bid-ask spread in an efficient market," The Journal of Finance, 39(4), 1127-1139. 
Schaefer, J. (1997): Analysis of incomplete multivariate data. Chapman and Hall, New York. 


\section{Appendix}

\section{A Additional Tables}

\begin{tabular}{|c|c|c|c|}
\hline TiCKer & COMPANy & Country & SECTOR \\
\hline $\mathrm{AZ}$ & AllianZ & Germany & FinANCIAL \\
\hline BASF & BASF & GERMANY & INDUSTRIALS \\
\hline BAY & BAYER & Germany & INDUSTRIALS \\
\hline BMW & BMW & GERMany & Automoвile \\
\hline CAR & CARrefour & FRANCE & CONSUMERs \\
\hline $\mathrm{DT}$ & Deutsche Telekom & GeRmany & $\mathrm{TMT}$ \\
\hline EDF & Electricite de France & FranCE & ENERGY \\
\hline $\mathrm{EN}$ & ENEL & ITALY & ENERGY \\
\hline FOT & ForTum OyI & FINLAND & ENERGY \\
\hline FTE & France Telecom & FRANCE & TMT \\
\hline GDF & GDF SuEz & FRANCE & ENERGY \\
\hline IBE & IBERDROLA & SPAIN & ENERGY \\
\hline $\mathrm{KPN}$ & KONINKLIJKE KPN & NETHERLANDS & TMT \\
\hline LVMH & LVMH & FRANCE & Consumers \\
\hline NGG & National GRID & UK & ENERGY \\
\hline REP & REPSOL & SPAIN & ENERGY \\
\hline RWE & RWE & GERMANy & ENERGY \\
\hline SGO & St Gobain & FranCE & INDUSTRIALS \\
\hline STD & Bco Santander Central Hispano & SPAIN & FINANCIAL \\
\hline TEF & Telefonica & SPAIN & $\mathrm{TMT}$ \\
\hline TIT & Telecom Italia & ITALY & TMT \\
\hline VAT & VATTENFALL & SwEDEN & ENERGY \\
\hline $\mathrm{VE}$ & VEOLIA & FRANCE & ENERGY \\
\hline VOW & VW & GERMANy & Automoвile \\
\hline
\end{tabular}

Table A.1: Reference entities. The table shows the ticker symbols, company names, country and industry sector of the sample reference entities. 


\section{B Estimation Details}

\section{A Construction of the likelihood function}

Denote the vector of price series by $y_{t}$, then conditional on the unobserved state variable $s_{t}$, the density function of $y_{t}$ is known. As the shocks were assumed to be conditionally normal, the conditional density of $y_{t}$ is given by

$$
f\left(y_{t} \mid s_{t}=j, Y_{t-1}\right)=(2 \pi)^{-\frac{n}{2}} \operatorname{det}\left(\Sigma_{j}\right)^{-\frac{1}{2}} \exp \left(-\frac{1}{2} u_{t} \Sigma_{j}^{-1} u_{t}\right)
$$

for $\mathrm{j}=1,2$ and $Y_{t-1}=y_{1}, \ldots, y_{t-1}$. Multiplying the conditional density with the marginal density of $s_{t}$ yields the joint density of $y_{t}$ and $s_{t}$

$$
f\left(y_{t}, s_{t}=j \mid Y_{t_{1}}\right)=\operatorname{Pr}\left(s_{t}=j \mid Y_{t-1}\right) f\left(y_{t} \mid s_{t}=j, Y_{t-1}\right)
$$

for $j=1,2$. Summing over all regimes allows to integrate out $s_{t}$ which results in the unconditional density of $y_{t}$ :

$$
f\left(y_{t} \mid Y_{t-1}\right)=\sum_{j=1}^{2} f\left(y_{t}, s_{t}=j \mid Y_{t-1}\right) .
$$

This density corresponds to the average of the conditional densities weighted by the probability of the particular regime. To compute the weighting factors, we have to account for the Markov structure of $s_{t}$. In time $t$, the probability of regime $j$ can be calculated as $\operatorname{Pr}\left(s_{t}=j \mid Y_{t-1}\right)=\operatorname{Pr}\left(s_{t}=j \mid s_{t-1}=i\right) \times$ $\operatorname{Pr}\left(s_{t-1}=j \mid Y_{t-1}\right)$ where the probabilities in the first term on the right hand side are summarized in the transition matrix $\mathbf{P}=\left[\begin{array}{cc}p_{11} & 1-p_{22} \\ 1-p_{11} & p_{22}\end{array}\right]$ with $p_{i j}=\operatorname{Pr}\left(s_{t}=j \mid s_{t-1}=i\right) \forall i, j \in 1,2$.

Using Bayes' theorem, the probability $\operatorname{Pr}\left(s_{t}=j \mid Y_{t}\right)$ can be filtered out, which together with the transition matrix $\mathrm{P}$ delivers $\operatorname{Pr}\left(s_{t+1}=j \mid Y_{t}\right)$. Iterating these steps until the last observation, generates $f\left(y_{t} \mid Y_{t-1}\right)$ for each point in time. Finally, the log-likelihood function is given by

$$
\log L_{T}=\sum_{t=1}^{t} \log f\left(y_{t} \mid Y t_{1}\right) .
$$

It is maximised with respect to $W, \Psi, p_{11}$ and $p_{22}$ (see equations (6) and $(7))$.

The main difficulty of this optimization approach concerns the search of appropriate initial values. Due to the complexity of the log-likelihood function, finding the global peak proves to be challenging. In order to verify the 
maximization results and to find a more reliable method in terms of starting values, we recommend to apply the EM-algorithm.

\section{B The EM-algorithm}

In this study, the approach described by Herwartz and Luetkepohl (2014) is implemented. It represents the EM-algorithm enhanced by a Baum/Lindgren/Hamilton/Kim (BLHK) filter which is elucidated by Krolzig (1997). Contrary to the approach of Herwartz and Luetkepohl (2014), we do not compute the residual series within the EM-algorithm, but estimate the VECM model in equation (1) and consequently use the VECM residuals in the optimization of the log-likelihood.

For notational clarification note that the term $\mathbf{1}_{2}$ denotes a $2 \times 1$ vector of ones. The transition matrix is named $P$. Besides,

$$
\xi_{t \mid s}=\left[\begin{array}{l}
\operatorname{Pr}\left(s_{t}=1 \mid Y_{s}\right) \\
\operatorname{Pr}\left(s_{t}=1 \mid Y_{s}\right)
\end{array}\right]
$$

$\odot$ stands for element-wise multiplication,

$\oslash$ stands for element-wise division and

$\otimes$ for the Kronecker product.

1. Initialization of the starting values: $P^{(0)}, \xi_{0 \mid 0}, W^{0}$ and $\Psi^{(0)}$.

2. Expectation step:

The expectation step of the EM-Algorithm begins with the filtering or a "forward recursion"

$$
\xi_{t \mid t}=\frac{\eta_{t} \odot P \xi_{t-1 \mid t-1}}{\mathbf{1}_{2}^{\prime}\left(\eta_{t} \odot P \xi_{t-1 \mid t-1}\right)} \text { for } t=1, \ldots, T
$$

where

$$
\eta_{t}=\left[\begin{array}{l}
f\left(y_{t} \mid s_{t}=1, Y_{t-1}\right) \\
f\left(y_{t} \mid s_{t}=2, Y_{t-1}\right)
\end{array}\right]
$$

with

$$
f\left(y_{t} \mid s_{t}=m, Y_{t-1}\right)=(2 \pi)^{-K / 2} \operatorname{det}\left(\Sigma_{m}\right)^{-1 / 2} \exp \left\{-\frac{1}{2} u_{t}^{\prime} \Sigma_{m}^{-1} u_{t}\right\} \quad \text { for } m=1,2 .
$$


Then, the filtered probabilities are smoothed by means of "backward recursion".

$$
\xi_{t \mid T}=\left(P^{\prime}\left(\xi_{t+1 \mid T} \oslash P \xi_{t \mid t}\right)\right) \odot \xi_{t \mid t} \text { for } t=T-1, \ldots, 0 .
$$

3. Maximization step:

Along the maximization step, the transition matrix is estimated with the Hidden Markov Chain formula (Krolzig (1997))

$$
\operatorname{vec}\left(\hat{P}^{\prime}\right)=\left(\sum_{t=1}^{T-1} \xi_{t \mid T}^{(2)}\right) \oslash\left(\mathbf{1}_{2} \otimes \sum_{t=1}^{T} \xi_{t \mid T}\right)
$$

where

$$
\xi_{t \mid T}^{(2)}=\operatorname{vec}\left(P^{\prime}\right) \odot\left[\left(\xi_{t+1 \mid T} \oslash P \xi_{t \mid t}\right) \otimes \xi_{t \mid t}\right] \text { for } t=0, \ldots, T-1 .
$$

Finally, the values of $W$ and $\Psi$, which maximize the expected loglikelihood function, have to be found. The expected $\log L_{t}$ is given by:

$$
\log L_{E M}=-\frac{1}{2} \sum_{t=1}^{T} \sum_{m=1}^{2} \xi_{m t \mid T}\left[2 \log (2 \pi)+\log \left(\left|\Sigma_{m}\right|\right)+u_{t}^{\prime} \Sigma_{m}^{-1} u_{t}\right]
$$

writing the regimes out, yields

$$
\begin{aligned}
& =-\frac{1}{2}\left[2 \log (2 \pi) \sum_{t=1}^{T} \xi_{1 t \mid T}+\sum \xi_{1 t \mid T} \log \left(\left|W W^{\prime}\right|\right)+\operatorname{tr}\left(\left(W W^{\prime}\right)^{-1} \sum_{t=1}^{T} \xi_{1 t \mid T} \hat{u}_{t}^{\prime} \hat{u}_{t}\right)\right. \\
& \left.+2 \log (2 \pi) \sum_{t=1}^{T} \xi_{2 t \mid T}+\sum \xi_{2 t \mid T} \log \left(\left|W \Psi W^{\prime}\right|\right)+\operatorname{tr}\left(\left(W \Psi W^{\prime}\right)^{-1} \sum_{t=1}^{T} \xi_{2 t \mid T} \hat{u}_{t}^{\prime} \hat{u}_{t}\right)\right]
\end{aligned}
$$

It is maximized subject to constraints on the $W$ and $\Psi$ matrices which were discussed in Section 2. In addtion, a lower bound of 0.001 is imposed on the determinant of each covariance matrix. The estimates become the initial values for the next iteration:

$\hat{P}=P^{(0)}$,

$\xi_{0 \mid T}=\xi_{0 \mid 0}$,

$\hat{W}=W^{0}$ and $\hat{\Psi}=\Psi^{(0)}$.

Step 2 and step 3 are iterated until convergence, e.g. until

$$
\sum_{i=1}^{2} \sum_{j=1}^{2}\left|\hat{W}_{i j}-W_{i j}^{(0)}\right|<0.00001
$$


Unfortunately, using numerical optimization does not guarantee a monotonic convergence of the expected log-likelihood (Schaefer (1997)). This is the case in our study as shown by figure B.1. Figure B.1. shows that using numerical optimization leads to non-monotonic convergence in our empirical application. Consequently we verify our results by applying both approaches, direct maximization of the loglikelihood function an the EM- algorithm outlined above.
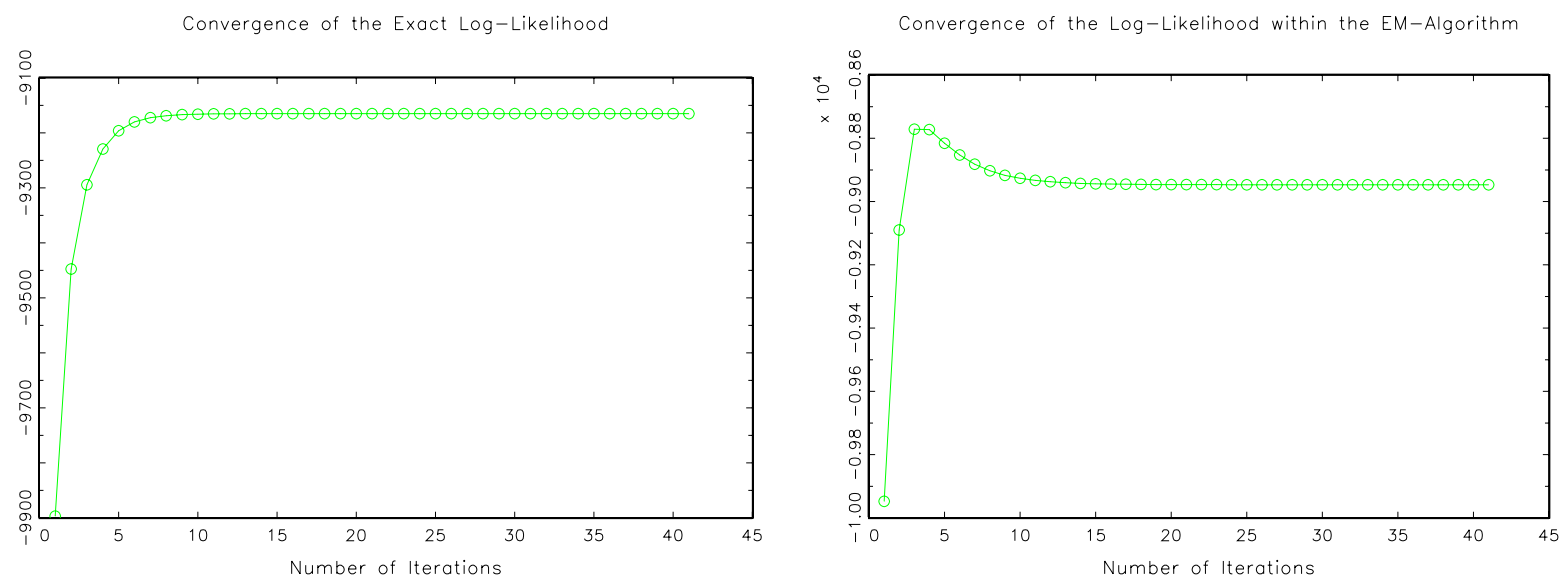

Figure B.1: Convergence of likelihood function

Standard errors of the estimates are obtained by means of a parametric bootstrap. This bootstrap is a slightly adapted version of the procedure described in Grammig and Peter (2013). It proves to be convenient, bearing in mind the two-step estimation structure.

Estimation is done in Gauss and all program codes are available upon request. 


\section{SFB 649 Discussion Paper Series 2015}

For a complete list of Discussion Papers published by the SFB 649, please visit http://sfb649.wiwi.hu-berlin.de.

001 "Pricing Kernel Modeling" by Denis Belomestny, Shujie Ma and Wolfgang Karl Härdle, January 2015.

002 "Estimating the Value of Urban Green Space: A hedonic Pricing Analysis of the Housing Market in Cologne, Germany" by Jens Kolbe and Henry Wüstemann, January 2015.

003 "Identifying Berlin's land value map using Adaptive Weights Smoothing" by Jens Kolbe, Rainer Schulz, Martin Wersing and Axel Werwatz, January 2015.

004 "Efficiency of Wind Power Production and its Determinants" by Simone Pieralli, Matthias Ritter and Martin Odening, January 2015.

005 "Distillation of News Flow into Analysis of Stock Reactions" by Junni L. Zhang, Wolfgang K. Härdle, Cathy Y. Chen and Elisabeth Bommes, January 2015.

006 "Cognitive Bubbles" by Ciril Bosch-Rosay, Thomas Meissnerz and Antoni Bosch-Domènech, February 2015.

007 "Stochastic Population Analysis: A Functional Data Approach" by Lei Fang and Wolfgang K. Härdle, February 2015.

008 "Nonparametric change-point analysis of volatility" by Markus Bibinger, Moritz Jirak and Mathias Vetter, February 2015.

009 "From Galloping Inflation to Price Stability in Steps: Israel 1985-2013" by Rafi Melnick and till Strohsal, February 2015.

010 "Estimation of NAIRU with Inflation Expectation Data" by Wei Cui, Wolfgang K. Härdle and Weining Wang, February 2015.

011 "Competitors In Merger Control: Shall They Be Merely Heard Or Also Listened To?" by Thomas Giebe and Miyu Lee, February 2015.

012 "The Impact of Credit Default Swap Trading on Loan Syndication" by Daniel Streitz, March 2015.

013 "Pitfalls and Perils of Financial Innovation: The Use of CDS by Corporate Bond Funds" by Tim Adam and Andre Guettler, March 2015.

014 "Generalized Exogenous Processes in DSGE: A Bayesian Approach" by Alexander Meyer-Gohde and Daniel Neuhoff, March 2015.

015 "Structural Vector Autoregressions with Heteroskedasticy" by Helmut Lütkepohl and Aleksei Netšunajev, March 2015.

016 "Testing Missing at Random using Instrumental Variables" by Christoph Breunig, March 2015.

017 "Loss Potential and Disclosures Related to Credit Derivatives - A CrossCountry Comparison of Corporate Bond Funds under U.S. and German Regulation" by Dominika Paula Gałkiewicz, March 2015.

018 "Manager Characteristics and Credit Derivative Use by U.S. Corporate Bond Funds" by Dominika Paula Gałkiewicz, March 2015.

019 "Measuring Connectedness of Euro Area Sovereign Risk" by Rebekka Gätjen Melanie Schienle, April 2015.

020 "Is There an Asymmetric Impact of Housing on Output?" by Tsung-Hsien Michael Lee and Wenjuan Chen, April 2015.

021 "Characterizing the Financial Cycle: Evidence from a Frequency Domain Analysis" by Till Strohsal, Christian R. Proaño and Jürgen Wolters, April 2015.

\section{SFB 649, Spandauer Straße 1, D-10178 Berlin http://sfb649.wiwi.hu-berlin.de}




\section{SFB 649 Discussion Paper Series 2015}

For a complete list of Discussion Papers published by the SFB 649, please visit http://sfb649.wiwi.hu-berlin.de.

022 "Risk Related Brain Regions Detected with 3D Image FPCA" by Ying Chen, Wolfgang K. Härdle, He Qiang and Piotr Majer, April 2015.

023 "An Adaptive Approach to Forecasting Three Key Macroeconomic Variables for Transitional China" by Linlin Niu, Xiu Xu and Ying Chen, April 2015.

024 "How Do Financial Cycles Interact? Evidence from the US and the UK" by Till Strohsal, Christian R. Proaño, Jürgen Wolters, April 2015.

025 "Employment Polarization and Immigrant Employment Opportunities" by Hanna Wielandt, April 2015.

026 "Forecasting volatility of wind power production" by Zhiwei Shen and Matthias Ritter, May 2015.

027 "The Information Content of Monetary Statistics for the Great Recession: Evidence from Germany" by Wenjuan Chen and Dieter Nautz, May 2015.

028 "The Time-Varying Degree of Inflation Expectations Anchoring" by Till Strohsal, Rafi Melnick and Dieter Nautz, May 2015.

029 "Change point and trend analyses of annual expectile curves of tropical storms" by P.Burdejova, W.K.Härdle, P.Kokoszka and Q.Xiong, May 2015.

030 "Testing for Identification in SVAR-GARCH Models" by Helmut LuetkepohI and George Milunovich, June 2015.

031 "Simultaneous likelihood-based bootstrap confidence sets for a large number of models" by Mayya Zhilova, June 2015.

032 "Government Bond Liquidity and Sovereign-Bank Interlinkages" by Sören Radde, Cristina Checherita-Westphal and Wei Cui, July 2015.

033 "Not Working at Work: Loafing, Unemployment and Labor Productivity" by Michael C. Burda, Katie Genadek and Daniel S. Hamermesh, July 2015.

034 "Factorisable Sparse Tail Event Curves" by Shih-Kang Chao, Wolfgang K. Härdle and Ming Yuan, July 2015.

035 "Price discovery in the markets for credit risk: A Markov switching approach" by Thomas Dimpfl and Franziska J. Peter, July 2015. 